OLIVEIRA, E.Q.; BEZERRA NETO, F.B.; NEGREIROS, M.Z.; BARROS JÚNIOR, A.P.; FREITAS, K.K.C.; SILVEIRA, L.M.; LIMA, J.S.S. Produção e valor agroeconômico no consórcio entre cultivares de coentro e de alface. Horticultura Brasileira, Brasília, v.23, n.2, p.285-289, abr-jun 2005.

\title{
Produção e valor agroeconômico no consórcio entre cultivares de coentro e de alface
}

\author{
Eliane Q. de Oliveira; Francisco Bezerra Neto; Maria Zuleide de Negreiros; Aurélio P. Barros Júnior; \\ Karidja Kalliany Carlos de Freitas; Lindomar Maria da Silveira; Jailma S.S. de Lima \\ ESAM, C. Postal:137, 59625-900 Mossoró-RN; e-mail: bezerra@esam.br.
}

\begin{abstract}
RESUMO
O experimento foi realizado de outubro a dezembro de $2003 \mathrm{em}$ campo, na ESAM, com o objetivo de avaliar agroeconomicamente cultivares comerciais de coentro consorciadas com cultivares de alface. O delineamento experimental usado foi de blocos completos casualizados em esquema fatorial 5 x 2 , com três repetições. Os tratamentos consistiram da combinação de cinco cultivares de coentro (Verdão, Supéria, Português, Asteca e Santo) com duas cultivares de alface (Tainá e Babá de Verão). Avaliaram-se a altura de plantas, número de hastes/planta, massa seca da parte aérea, número de molhos comerciáveis $/ \mathrm{m}^{2}$ e rendimento estimado de massa verde no coentro, e, altura e diâmetro de plantas, número de folhas/planta, massa seca da parte aérea e produtividade estimada na alface. Alguns indicadores agroeconômicos foram usados para medir a eficiência biológica e econômica dos sistemas consorciados. Houve interação entre as cultivares de alface e de coentro na altura de plantas, número de molhos $/ \mathrm{m}^{2}$ e no rendimento estimado de massa verde do coentro, com a cultivar de coentro Português registrando a melhor performance produtiva quando combinada com ambas as cultivares de alface. As cultivares de alface tiveram desempenho produtivo diferente, com a cultivar Babá de Verão significativamente superior à Tainá. Em todos os sistemas consorciados foram observadas eficiências agroeconômicas, porém as maiores foram registradas nos consórcios entre as cultivares Tainá e Asteca, e Babá de Verão e Português.
\end{abstract}

Palavras-chave: Coriandrum sativum, Lactuca sativa, desempenho agroeconômico.

\begin{abstract}
Yield and agroeconomic values through intercropping of coriander and lettuce cultivars

The experiment was carried from October to December 2003, in the field, to evaluate the production and agrieconomic performance of coriander cultivars intercropped with lettuce cultivars. The experimental design was of randomized complete blocks in a $5 \times 2$ factorial scheme, with three replications. The treatments consisted of the combination of five coriander cultivars (Verdão, Superia, Português, Asteca and Santo) with two lettuce cultivars (Tainá and Babá de Verão). Evaluations of plant height, number of stalks/plant, shoot dry matter, number of marketable bunches $/ \mathrm{m}^{2}$ and estimated yield of green mass were made from the coriander crop. Plant height and diameter, number of leaves/plant, leaf dry matter and estimate yield were obtained from the lettuce crop. Agrieconomic indicators were used to measure the efficiency of intercropping systems. There was a significant interaction between coriander and lettuce cultivars on plant height, number of marketable bunches $/ \mathrm{m}^{2}$ and green mass estimated yield, with coriander cv. Português presenting the best performance in yield, in combination with both lettuce cultivars. The lettuce cultivars presented different yield performance, with lettuce cv. Babá de Verão being the most productive. Agrieconomic efficiencies were observed in all intercropping systems, but the highest efficiencies were registered in the combination of 'Tainá'/ 'Asteca' and 'Babá de Verão'/ 'Português'.
\end{abstract}

Keywords: Coriandrum sativum, Lactuca sativa, agrieconomic performance.

(Recebido para publicação em 20 de abril de 2004 e aceito em 20 de janeiro de 2005)

$M$ uitas olerícolas encontram no Brasil condições edafoclimáticas favoráveis (SACRAMENTO, 2000), mas seus cultivos e comercialização ainda não são expressivos. O coentro (Coriandrum sativum L.) é uma das hortaliças mais comuns na culinária, cujas folhas e sementes são utilizadas na composição e decoração de diversos pratos regionais. A cultura se adapta bem em regiões de clima quente e se mostra intolerante a baixas temperaturas (FILGUEIRA, 2000). Seu cultivo é praticado por pequenos produtores, em hortas domésticas, escolares e comunitárias, e não objetiva apenas a produção de massa verde, comercializada em feiras livres e supermercados, mas também a produção de frutos, utilizados nas indústrias alimentícia e cosmética. Por apresentar precocidade em seu ciclo (45-60 dias), esta cultura garante retorno rápido do capital investido, aumentando a renda das famílias envolvidas na exploração, viabilizando a mão-de-obra familiar ociosa, tornando-se, então, uma espécie de notável alcance social (HAAG; MINAMI, 1998).

Segundo Ehlers (1999), um dos componentes comum às mais diversas tendências envolvidas na transição para a agricultura sustentável é o incentivo à substituição de sistemas simplificados por agrossistemas diversificados, como a consorciação de culturas. O potencial deste sistema relaciona-se com o aumen- to da eficiência de exploração dos recursos naturais e do uso da terra, além de conferir proteção contra pragas e doenças e de reduzir a pressão exercida por plantas espontâneas sobre as culturas (ALTIERI, 1995; LIEBMAN, 1995; SANTOS, 1998).

A associação de coentro com alface tem se tornado uma combinação desejável entre as hortaliças, capaz de proporcionar maior índice de uso de eficiência da terra e retorno econômico por área (FREITAS, 2003), além de se complementarem em termos de valor nutricional (CAMBODIA, 1993).

No Rio Grande do Norte, e em alguns outros estados do Nordeste, o coentro é cultivado por pequenos pro- 
dutores, em cultivo solteiro e destituído de técnicas e manejos adequados, levando a uma queda considerável no rendimento da cultura e no desperdício da produção. Com o aparecimento de novas cultivares tanto de coentro como de alface, em fase de adaptação às condições do Nordeste brasileiro, torna-se importante a busca de informações e a obtenção de dados comparativos sobre o comportamento destes materiais em agroecossistemas consorciados. Busca-se cultivares que proporcionem boa capacidade de combinação interespecífica e, consequentemente, maior produção e eficiência agroeconômica nesses sistemas.

A fim de obter subsídios para o desenvolvimento de sistemas consorciados sustentáveis de coentro e alface, avaliouse no presente trabalho cultivares comerciais de coentro adaptadas às condições do Nordeste brasileiro, em sistema consorciado com cultivares de alface.

\section{MATERIAL E MÉTODOS}

Realizou-se o experimento em campo da ESAM, de outubro a dezembro de 2003, em solo Argissolo Vermelho Amarelo Eutrófico. Amostras de solo foram processadas e analisadas em laboratório revelando: $\mathrm{pH}$ (água 1:2,5) = 7,55; $\mathrm{Ca}=7,12 \mathrm{cmol}_{\mathrm{c}} \mathrm{dm}^{-3} ; \mathrm{Mg}=4,02$ $\mathrm{cmol}_{\mathrm{c}} \mathrm{dm}^{-3} ; \mathrm{K}=0,60 \mathrm{cmol}_{\mathrm{c}} \mathrm{dm}^{-3} ; \mathrm{Na}=$ $0,25 \mathrm{cmol} \mathrm{dm}^{-3} ; \mathrm{Al}=0,00 \mathrm{cmol}_{\mathrm{c}} \mathrm{dm}^{-3} \mathrm{e}$ $\mathrm{P}=554 \mathrm{mg} \mathrm{dm}^{-3}$. O clima da região, de acordo com a classificação Köppen, é BSwh', isto é, seco e muito quente, com duas estações climáticas: uma seca (junho a janeiro) e uma chuvosa (fevereiro a maio). A temperatura média e máxima no período cultivado foi de $29,7^{\circ} \mathrm{C}$ e $35,5^{\circ} \mathrm{C}$, com um fotoperiodo médio de 10,17 horas.

Utilizou-se o delineamento de blocos completos casualizados com três repetições, sendo os tratamentos arranjados em esquema fatorial 5 x 2 . Os tratamentos resultaram da combinação de cinco cultivares de coentro (Verdão, Supéria, Português, Asteca e Santo) com duas cultivares de alface (Tainá e Babá de Verão). O cultivo consorciado foi estabelecido na forma de faixas alternadas de quatro fileiras das culturas, ladeadas por uma fileira guarda ou bordadura. $\mathrm{O}$ espaçamento entre as fai- xas de plantio e a bordadura foi de 0,80 $\mathrm{m}$, e entre e dentro de fileiras foi de 0,20 x $0,05 \mathrm{~m}$ para o coentro, com duas plantas por cova, e de $0,20 \times 0,10 \mathrm{~m}$ para a alface. A área total de cada parcela consorciada foi de $2,40 \mathrm{~m}^{2}$, com uma área útil de $1,60 \mathrm{~m}^{2}$. O número de plantas na área útil foi de 160 para o coentro e de 40 para a alface.

Em cada bloco, foram plantadas parcelas solteiras das cultivares de coentro e de alface para obtenção dos indicadores agroeconômicos, nos espaçamentos de $0,20 \times 0,10 \mathrm{~m}$ para o coentro, com duas plantas por covas, e de 0,20 x 0,20 $\mathrm{m}$ para a alface, com uma área total de $1,20 \mathrm{~m}^{2}$ e uma área útil de $0,60 \mathrm{~m}^{2}$ para o coentro e $0,48 \mathrm{~m}^{2}$ para a alface, contendo 60 e 12 plantas de ambas culturas. $\mathrm{O}$ espaçamento dentro das fileiras de cada cultura no consórcio foi diferente do cultivo solteiro, para que fosse mantida constante a população em ambos os sistemas. A população teórica recomendada para o cultivo solteiro na região, é de 1.000 .000 plantas para o coentro (FREITAS, 2003) e de 250.000 plantas para a alface (SILVA, 1999), sem levar em consideração os $30 \%$ de área de trânsito, composta de corredores e estradas.

Nos canteiros de plantio, previamente solarizados por 60 dias, fez-se adubação com $80 \mathrm{t} \mathrm{ha}^{-1}$ de esterco de bovinos, com $30 \mathrm{~kg} \mathrm{ha}^{-1}$ de nitrogênio, na forma de uréia, $60 \mathrm{~kg} \mathrm{ha}^{-1}$ de $\mathrm{P}_{2} \mathrm{O}_{5}$, na forma de superfosfato simples e $30 \mathrm{~kg}$ ha $^{-1}$ de $\mathrm{K}_{2} \mathrm{O}$, na forma de cloreto de potássio, de acordo com a análise realizada no solo. Realizou-se uma adubação nitrogenada em cobertura, aos 15 dias após o transplantio da alface, com 40 $\mathrm{kg} \cdot \mathrm{ha}^{-1}$ de uréia. Efetuaram-se também adubações foliares de $30 \mathrm{ml} / 20 \mathrm{ml}$ de água na formulação $14 \%$ de N, $4 \%$ de $\mathrm{P}_{2} \mathrm{O}_{5}, 6 \%$ de $\mathrm{K}_{2} \mathrm{O}, 0,8 \%$ de $\mathrm{S}, 1,5 \%$ de $\mathrm{Mg}, 2 \%$ de $\mathrm{Zn}, 1,5 \%$ de $\mathrm{Mn}, 0,1 \%$ de B e $0,05 \%$ de Mo, aos 21 e 26 dias após a semeadura da alface. No coentro, realizaram-se duas adubações foliares, aos 15 e aos 25 dias após a semeadura.

A alface foi semeada em 22 de outubro de 2003, em copos descartáveis de $150 \mathrm{ml}$, contendo como substrato comercial uma mistura de fibra de coco e composto orgânico na proporção de 1:2. Semeou-se de três a cinco sementes por recipiente e, aos três dias após a germinação, efetuou-se o primeiro desbaste, deixando-se duas plântulas. Aos oito dias, foi feito o segundo desbaste, deixando-se apenas uma plântula por recipiente. As mudas foram produzidas em uma estufa coberta com plástico branco leitoso. As mudas de alface foram transplantadas para as faixas adjacentes do coentro aos 20 dias após a semeadura, quando o coentro semeado diretamente nas covas em 11/10/2003, encontravase com cinco dias de plantio. Realizouse o desbaste do coentro dezoito dias após a semeadura, deixando-se apenas duas plantas por cova.

Durante a realização do experimento, efetuaram-se capinas manuais e a irrigação foi realizada por micro-aspersão. A colheita da alface se deu em 05/ $12 / 2003$. O coentro Verdão foi colhido em 20/12/2003, aos 43 dias após semeadura e as demais cultivares foram colhidas em 31/12/2003, aos 54 dias após semeadura.

Do coentro avaliou-se a altura de plantas (determinada em uma amostra de dez plantas escolhidas aleatoriamente na parcela útil, a partir do nível do solo até a extremidade das folhas mais altas, expressa em $\mathrm{cm}$ ), número de hastes por planta (determinado na mesma amostra de dez plantas, contando-se o número de hastes por planta, expresso em termos de média), massa seca da parte aérea (determinada da mesma amostra anterior, o peso seco em estufa com circulação forçada de ar a $70^{\circ} \mathrm{C}$ até atingir peso constante, expressa em $\mathrm{t} \mathrm{ha}^{-1}$ ), número de molhos $/ \mathrm{m}^{2}$ (obtido em molhos de $100 \mathrm{~g}$ de plantas, constituídos de hastes e folhas) e rendimento de massa verde estimado (obtido utilizando-se o peso da massa fresca das plantas da área útil da parcela, expresso em t ha-1).

Da alface avaliaram-se a altura (realizada em uma amostra de cinco plantas escolhidas aleatoriamente na parcela útil, a partir do nível do solo até a extremidade das folhas mais altas, expressa em $\mathrm{cm}$ ) e diâmetro de plantas (realizado nas mesmas cinco plantas da amostra, medindo-se a distância entre as margens opostas do disco foliar, por ocasião da colheita, expressa em cm), número de folhas por planta (determinado na mesma amostra de cinco plantas, 
Produção e valor agroeconômico no consórcio entre cultivares de coentro e de alface

Tabela 1. Altura de plantas, número de molhos. $\mathrm{m}^{-2}$, rendimento estimado de massa verde, número de hastes por planta e massa seca da parte aérea de cultivares comerciais de coentro em consórcio com cultivares de alface. Mossoró, ESAM, 2003.

\begin{tabular}{|c|c|c|c|c|c|c|c|c|}
\hline \multirow{3}{*}{$\begin{array}{l}\text { Cultivares de } \\
\text { coentro }\end{array}$} & \multicolumn{6}{|c|}{ Cultivares de alface ${ }^{*}$} & \multirow{3}{*}{$\begin{array}{c}\text { Número de } \\
\text { hastes por } \\
\text { planta }\end{array}$} & \multirow{3}{*}{$\begin{array}{c}\text { Massa } \\
\text { seca da } \\
\text { parte aérea } \\
\left(\text { t. ha }^{-1}\right)\end{array}$} \\
\hline & Tainá & $\begin{array}{l}\text { Babá de } \\
\text { Verão }\end{array}$ & Tainá & $\begin{array}{l}\text { Babá de } \\
\text { Verão }\end{array}$ & Tainá & Babá de Verão & & \\
\hline & \multicolumn{2}{|c|}{ Altura de plantas $(\mathrm{cm})$} & \multicolumn{2}{|c|}{$\mathrm{N}^{\circ}$ de molhos $\mathrm{m}^{-2}$} & \multicolumn{2}{|c|}{$\begin{array}{c}\text { Rendimento estimado de massa } \\
\left.\text { verde (t.ha- }{ }^{-1}\right)\end{array}$} & & \\
\hline Verdão & $19,70 \mathrm{aA}$ & $20,10 \mathrm{bA}$ & $6,0 \mathrm{bA}$ & $5,9 \mathrm{bA}$ & 6,005 bA $(100 \%)$ & 5,908 bA $(100 \%)$ & $5,90 \quad c$ & $0,0273 \quad c$ \\
\hline Supéria & 17,95 a $B$ & $24,25 \mathrm{bA}$ & $5,5 \mathrm{bB}$ & $8,3 \mathrm{bA}$ & 5,461 bB $(91 \%)$ & 8,295 bA (140\%) & $10,02 a b$ & $0,0928 a b$ \\
\hline Português & 18,90 a $B$ & 35,30 aA & $10,1 \mathrm{aB}$ & $16,7 \mathrm{aA}$ & 10,123 aB (169\%) & $16,712 \mathrm{aA}(283 \%)$ & $11,20 \mathrm{a}$ & $0,1150 \mathrm{a}$ \\
\hline Asteca & 20,10 a $B$ & $31,10 \mathrm{aB}$ & $6,6 \mathrm{bA}$ & $8,5 \mathrm{bA}$ & 6,612 bA (110\%) & 8,527 bA (144\%) & $10,07 a b$ & $0,0721 a b$ \\
\hline Santo & $17,38 \mathrm{aA}$ & $18,85 \mathrm{bA}$ & $4,6 \mathrm{bA}$ & $5,3 \mathrm{bA}$ & 4,589 bA $(76 \%)$ & 5,245 bA & $9,07 \mathrm{ab}$ & $0,0539 a b$ \\
\hline \multicolumn{9}{|l|}{ Cultivares de alface } \\
\hline Tainá & & & & & & & $8,29 \mathrm{a}$ & 0,0593 a \\
\hline Babá de Verão & & & & & & & $10,50 \mathrm{a}$ & 0,0920 a \\
\hline CV (\%) & \multicolumn{2}{|c|}{6,14} & \multicolumn{2}{|c|}{18,32} & \multicolumn{2}{|c|}{18,28} & 15,96 & 32,17 \\
\hline
\end{tabular}

*Para cada variável, as médias seguidas pelas letras maiúsculas diferentes nas linhas e pelas letras minúsculas diferentes nas colunas diferem entre si pelo teste de Tukey a $5 \%$ de probabilidade.

contando-se o número de folhas maiores que $3 \mathrm{~cm}$ de comprimento, partindo-se das folhas basais até a última folha aberta), massa seca da parte aérea (tomada da mesma amostra anterior, onde se determinou o peso seco em estufa com circulação forçada de ar a $70^{\circ} \mathrm{C}$ até atingir peso constante, expressa em $\mathrm{t} \mathrm{ha}^{-1}$ ) e produtividade estimada (avaliada utilizando-se o peso da massa fresca da parte aérea de todas as plantas da parcela útil, expressa em $\mathrm{t} \mathrm{ha}^{-1}$ ).

Alguns indicadores agroeconômicos foram usados para medir a eficiência dos sistemas consorciados (BELTRÃO et al. 1984): índice de uso eficiente da terra (UET), renda bruta (RB), renda líquida (RL), vantagem monetária (VM), vantagem monetária corrigida (VMc), taxa de retorno (TR) e índice de lucratividade (IL). O índice UET é dado pela seguinte expressão: $\left(\mathrm{I}_{\text {coentro }} / \mathrm{S}_{\text {coentro }}\right)+\left(\mathrm{I}_{\text {alface }} /\right.$ $\mathrm{S}_{\text {alface}}$ ), onde I e $\mathrm{S}$ representam as produtividades dos sistemas consorciado e solteiro de cada cultura componente. É definido como a área relativa de terra sob condições de plantio isolado, que é requerida para proporcionar as produtividades alcançadas no consórcio.

A renda bruta $(\mathrm{RB})$ foi obtida multiplicando-se a produtividade da cultura em cada tratamento pelo valor do produto pago ao produtor no mês de outubro de 2003 . Foi de $\mathrm{R} \$ 1,50 / \mathrm{kg}$ para o coentro e de $\mathrm{R} \$ 1,20 / \mathrm{kg}$ e $\mathrm{R} \$ 1,30$ para as cultivares de alface Tainá e Babá de
Verão, respectivamente. A renda líquida (RL) foi calculada subtraindo-se da renda bruta, os custos de produção, provenientes de insumos mais serviços. Estes custos (C) foram calculados para cada tratamento, levando-se em conta os coeficientes de custo de insumos e os serviços utilizados em um hectare de coentro e alface a nível experimental. Foram considerados os preços de insumos e serviços vigentes no mês de outubro de 2003, na cidade de Mossoró. A vantagem monetária e a vantagem monetária corrigida foram obtidas pelas seguintes expressões: $\mathrm{VM}=\mathrm{RB} \mathrm{x}$ $($ UET - 1)/UET e VMc = RL x $($ UET-1)/ UET. A taxa de retorno (TR) por real investido em cada tratamento foi obtida por meio da relação entre a renda bruta (RB) e o custo de produção (C) de cada tratamento. $\mathrm{O}$ índice de lucratividade (IL) foi obtido da relação entre a RL e $\mathrm{RB}$ e expresso em percentagem.

Para avaliar as características do coentro e da alface supracitadas, utilizou-se a análise de variância univariada para o delineamento de blocos completos casualizados em esquema fatorial 5 x 2. O software utilizado na análise foi o SPSS/PC (Norusis, 1990).

\section{RESULTADOS E DISCUSSÃO}

Observou-se interação significativa entre cultivares de coentro e cultivares de alface na altura de plantas, número de molhos $\mathrm{m}^{-2}$ e no rendimento estimado de massa verde de coentro (Tabela 1). Desdobrando esta interação, não se observaram diferenças significativas entre as cultivares de coentro para altura de plantas quando consorciadas com a cultivar Tainá. Por outro lado, as cultivares Português e Asteca se sobressaíram das demais na altura de plantas, no consórcio com a cultivar de alface Babá de Verão. Com relação ao número de molhos $\mathrm{m}^{-2}$ e rendimento estimado de massa verde de coentro, apenas a cultivar Português se destacou das demais, independente da cultivar de alface consorciada (Tabela 1). Estes resultados divergem dos encontrados por Marques e Lorencetti (1999) que, avaliando as cultivares de coentro Verdão, Português e Palmeira em cultivo solteiro, observaram que a cultivar Verdão foi a que teve melhor desempenho produtivo.

Ao comparar-se as duas cultivares de alface, verificou-se maiores alturas de plantas de coentro das cultivares Supéria, Português e Asteca no consórcio com alface 'Babá de verão', em comparação às alturas verificadas no consórcio com alface 'Tainá'. Em relação ao número de molhos $\mathrm{m}^{-2}$ e rendimento estimado de massa verde, as cultivares Supéria e Português tiveram maiores valores no consórcio com a alface 'Babá de Verão', em comparação aos verificados no consórcio com alface 'Tainá' (Tabela 1). 
Tabela 2. Altura (AP) e diâmetro (DP) de plantas, número de folhas por planta (NF), massa seca da parte aérea (MSPA) e produtividade estimada (PE) de alface em consórcio com cultivares comerciais de coentro. Mossoró, ESAM, 2003.

\begin{tabular}{lccccc}
\hline Cultivares de alface & AP $(\mathbf{c m})^{*}$ & DP $(\mathbf{c m})$ & NF & MSPA (t.ha- (1) $^{\text {PE (t.ha- }}$ ( $^{-1}$ \\
\hline Tainá & $16,02 \mathrm{~b}$ & $18,45 \mathrm{~b}$ & $15,65 \mathrm{~b}$ & $0,1179 \mathrm{~b}$ & $17,69 \mathrm{~b}$ \\
Babá de Verão & $18,21 \mathrm{a}$ & $20,01 \mathrm{a}$ & $28,33 \mathrm{a}$ & $0,1318 \mathrm{a}$ & $20,52 \mathrm{a}$ \\
\hline Cultivares de coentro & & & & & \\
\hline Verdão & $17,18 \mathrm{a}$ & $18,55 \mathrm{a}$ & $21,33 \mathrm{a}$ & $0,1200 \mathrm{a}$ & $18,77 \mathrm{a}$ \\
Supéria & $16,30 \mathrm{a}$ & $18,82 \mathrm{a}$ & $22,17 \mathrm{a}$ & $0,1221 \mathrm{a}$ & $18,46 \mathrm{a}$ \\
Português & $18,02 \mathrm{a}$ & $20,07 \mathrm{a}$ & $22,50 \mathrm{a}$ & $0,1267 \mathrm{a}$ & $20,16 \mathrm{a}$ \\
Asteca & $17,45 \mathrm{a}$ & $19,57 \mathrm{a}$ & $21,17 \mathrm{a}$ & $0,1361 \mathrm{a}$ & $19,92 \mathrm{a}$ \\
Santo & $16,63 \mathrm{a}$ & $19,17 \mathrm{a}$ & $22,54 \mathrm{a}$ & $0,1192 \mathrm{a}$ & $18,19 \mathrm{a}$ \\
\hline CV (\%) & 10,16 & 10,13 & 11,22 & 11,46 & 10,35 \\
\hline
\end{tabular}

*Para cada variável, as médias seguidas por letras diferentes nas colunas, diferem entre si pelo teste de Tukey, ao nível de 5\% de probabilidade.

Com relação ao número de hastes planta $^{-1}$ e massa seca da parte aérea de coentro, foi observado apenas efeito significativo das cultivares de coentro, sendo que a cultivar Português registrou os maiores valores para essas características, embora tivesse diferido significativamente apenas da cultivar Verdão (Tabela 1).

A diferenciação nos desempenhos das cultivares comerciais de coentro, pode ser explicada presumivelmente pelas condições de alta temperatura e ampla luminosidade, além da adaptabilidade diferenciada destes genótipos a consorciação com alface. Outro fator que talvez tenha estimulado esta diferenciação foi o tempo de germinação. As cultivares Superia, Português, Asteca e Santo tiveram em média uma germinação de cinco dias a mais, quando comparada com a cultivar Verdão, que é a tipicamente plantada na região. Por vez esta demora na geminação, aumentou o ciclo dessas cultivares em onze dias. Este aumento pode ter influenciado no desempenho dessas cultivares. Pereira e Nascimento (2003), avaliando os efeitos de diferentes temperaturas na germinação das sementes de cultivares de coentro, de sete cultivares comerciais, concluíram que todas as cultivares avaliadas foram sensíveis a altas temperaturas, possivelmente devido à termo-inibição, uma vez que essas sementes germinaram ao serem transferidas para uma temperatura de $20^{\circ} \mathrm{C}$.

Nas características avaliadas na alface, observou-se apenas efeito significativo de cultivares de alface, com a cultivar Babá de Verão significativamente superior a Tainá (Tabela 2). Este resultado discorda em parte do obtido por Oliveira (2003), onde o desempe- nho produtivo da cultivar Tainá foi superior ao da Babá de Verão, quando consorciadas com cenoura. Isto indica que a cultivar Babá de Verão se adaptou melhor ao consórcio com o coentro do que a cultivar Tainá.

Os indicadores agroeconômicos dos sistemas consorciados oriundos das combinações das cultivares de alface com as cultivares de coentro, encontram-se na Tabela 3. Maiores eficiências biológicas e econômicas foram observadas nas combinações de cultivares Tainá e Asteca, e Babá de Verão e Português, cujo indicadores foram: índices de uso da terra de 1,62 e 3,21; rendas brutas de $\mathrm{R} \$ 38.040,80$ e $\mathrm{R} \$ 38.439,70$; rendas líquida de $\mathrm{R} \$ 23.085,60$ e $\mathrm{R} \$$ 23.717,22; vantagens monetária corrigida de $\mathrm{R} \$ 8.907,66$ e $\mathrm{R} \$ 16.286,28$; taxas de retorno de 2,54 e 2,61 e índices de lucratividade de $60,11 \%$ e $61,46 \%$, respectivamente (Tabela 3).

Como se pode observar, o melhor aproveitamento dos fatores ambientais disponíveis se deu nos sistemas consorciados, em relação ao sistema solteiro, uma vez que os índices de uso da terra (UETs) foram maiores que 1 (a unidade), variando de $42 \%$ a $221 \%$. Isto significa que são necessários de $42 \%$ a $221 \%$ a mais de área para que as culturas no plantio isolado produzam o equivalente à produção do consórcio em um hectare. Estes resultados confirmam em parte os obtidos por Freitas (2003) que obteve índices de uso eficiente da terra de $26 \%$ e $76 \%$ em sistemas consorciados de alface $\mathrm{x}$ coentro.

Tabela 3. Indicadores agroeconômicos de sistemas consorciados de cultivares de alface com cultivares comerciais de coentro. Mossoró, ESAM, 2003.

\begin{tabular}{lccccccc}
\hline Sistemas consorciados & UET & RB (R\$/ha) & RL (R\$/ha) & VM (R\$/ha) & VMc (R\$/ha) & TR & IL $(\%)$ \\
\hline Tainá + Verdão & 2,57 & $26.503,70$ & $12.109,50$ & $15.435,71$ & $7.080,70$ & 1,84 & 44,99 \\
Tainá + Supéria & 1,97 & $30.360,80$ & $15.609,60$ & $14.152,52$ & $7.582,99$ & 2,09 & 51,23 \\
Tainá + Português & 1,42 & $34.027,30$ & $18.910,82$ & $9.209,39$ & $4.983,96$ & 2,25 & 55,13 \\
Tainá + Asteca & 1,62 & $38.040,80$ & $23.085,60$ & $14.478,82$ & $8.907,66$ & 2,54 & 60,11 \\
Tainá + Santo & 1,81 & $31.885,50$ & $17.331,34$ & $14.044,99$ & $7.730,79$ & 2,19 & 52,68 \\
Babá de Verão + Verdão & 2,70 & $27.266,08$ & $13.266,08$ & $15.861,93$ & $7.382,65$ & 1,95 & 43,64 \\
Babá de Verão + Supéria & 2,86 & $29.913,20$ & $15.736,00$ & $18.064,28$ & $9.657,87$ & 2,11 & 52,10 \\
Babá de Verão + Português & 3,21 & $38.439,70$ & $23.717,22$ & $26.301,56$ & $16.286,28$ & 2,61 & 61,46 \\
Babá de Verão + Asteca & 2,06 & $36.278,40$ & $21.717,20$ & $17.628,59$ & $10.802,17$ & 2,49 & 59,31 \\
Babá de Verão + Santo & 1,60 & $27.510,30$ & $13.350,14$ & $9.840,92$ & $4.901,30$ & 1,94 & 48,24 \\
\hline
\end{tabular}

UET = Índice de Uso da Terra; RB= Renda Bruta; RL = Renda Líquida; VM = Vantagem Monetária (R\$); VMc = Vantagem Monetária corrigida (R\$); TR = Taxa de Retorno; IL = Índice de Lucratividade 
Por apresentar hábitos de crescimento e desenvolvimento temporal distintos, pode-se observar que as combinações entre cultivares de alface e de coentro, de modo geral, expressaram as vantagens no uso eficiente da terra em termos monetários, indicando que a superioridade agronômica obtida nelas traduziu-se em ganho econômico. É possível ressaltar também, que a escolha do tipo de consorciação deverá levar em consideração as peculiaridades de cada região e a preferência do mercado.

\section{LITERATURA CITADA}

ALTIERI, M.A. Traditional agriculture. In ALTIERI, M.A. (ed.). Agroecology: the science of sustainable agriculture. $2^{\text {nd }}$ ed. Boulder Cole: Wesview Press, 1995. p.107-144.

BELTRÃO, N.E.M. Comparação entre indicadores agroeconômicos de avaliação de agroecossistemas consorciados e solteiros envolvendo algodão "upland" e feijão "caupi". Campina Grande: CNPA, 1984. 21p. (Boletim de pesquisa 15).
CAMBODIA, S.S. Crop protection in home garden through companion cropping. Thailand: ARC-AVRDC, 1993. 7p.

EHLERS, E. Agricultura sustentável: origens e perspectivas de um novo paradigma. 2 ed. Guaíba: Agropecuária, 1999. $157 \mathrm{p}$.

FILGUEIRA, F.A.R. Novo manual de olericultura: agrotecnologia moderna na produção e comercialização de hortaliças. Viçosa: UFV, 2000. 402 p.

FREITAS, K.K.C. Uso de água de rio e efluente de peixes em consórcios: cenoura x alface, cenoura $x$ coentro e alface $x$ coentro em faixas. 2003 45 f. (Monografia graduação) - ESAM, Mossoró, $\mathrm{RN}$.

HAAG, H.P.; MINAMI, K. Nutrição mineral em hortaliças. $2^{\mathrm{a}}$ ed., Campinas: Fundação Cargill, 1998. p.28-29.

LIEBMAN, M. Polyculture crop systems. In: ALTIERI, M.A. (ed.). Agroecology: the science of sustainable agriculture. $2^{\text {nd }}$ ed. Boulder Cole: Westview Press, 1995. p.205-218.

MARQUES, F.C.; LORENCETTI, B.L. Avaliação de três cultivares de coentro (Coriandrum sativum L.) semeadas em duas épocas. Pesquisa Agropecuária Gaúcha, Porto Alegre, v.5, n.2, p.265-270, 1999.

NORUSIS, M.J. SPSS/PC Statistics. Illinois: SPSS Inc., 1990. 320 p.
OLIVEIRA, E.Q. Desempenho agroeconômico do bicultivo de alface consorciada, em faixa, com cenoura. 2004. 76 f. (Tese mestrado) - ESAM, Mossoró, RN.

PEREIRA, R.S.; NASCIMENTO, W.M. Germinação de sementes de coentro sob diferentes temperaturas. Horticultura Brasileira, Brasília, 2003. Disponível em: 〈http://horticiencia.com.br/anais>. Acesso em: 26 jan. 2003. Trabalho apresentado no $42^{\circ}$ Congresso Brasileiro de Olericultura, 2003. SACRAMENTO, C.K. Aspectos agronômicos de plantas condimentares. Horticultura brasileira, v.18, Suplemento julho, $2000.40^{\circ}$ Congresso Brasileiro de Olericultura. Revista da Sociedade de Olericultura do Brasil.

SANTOS, R.H.S. Interações interespecíficas em consórcio de olerícolas. 1998. 129 f. (Tese doutorado) - UFV, Viçosa, MG.

SILVA, V.F. Cultivares de alface em diferentes espaçamentos sob temperatura e luminosidade elevadas. 1999. 25 f. (Tese mestrado) - ESAM, Mossoró-RN. 